\title{
Climas urbanos y contaminación atmosférica en Santiago de Chile
}

\author{
Hugo Romero \\ Felipe Irarrázaval \\ Dustyn Opazo \\ Marcela Salgado \\ Pamela Smitb
}

Laboratorio de Medio Ambiente y Territorio, Departamento de Geografía, Facultad de Arquitectura y Urbanismo, Universidad de Chile.

RESUMEN | Se analizan las relaciones existentes entre temperaturas urbanas y concentraciones de material particulado a una escala que representa la totalidad de la ciudad, destacando su división en dos zonas bien delimitadas, que ubicadas al oriente y poniente de la misma, durante los días de ocurrencia de las peores condiciones de contaminación atmosférica. A escala más detallada, que representa a tipos característicos de morfología urbana, se correlacionan los usos y coberturas de suelos con los niveles de vegetación y las temperaturas de las llamadas "subzonas climáticas”, en las comunas de Peñalolén, Santiago Centro y Cerrillos, que representan diversas localizaciones en los espacios naturales y socioeconómicos de la ciudad, concluyéndose que existen áreas de condiciones adversas para la población y configuraciones que resaltan su heterogeneidad y diversidad.

PALABRAS CLAVE | Medio ambiente urbano, calidad ambiental y sustentabilidad urbana.

\begin{abstract}
Current relationships between urban temperatures and particulate matter concentrations at a scale that is representative of the whole city have been analyzed, highlighting a clear division in two zones, the eastern and western part of the city during the days that register the worst air pollution. On a more detailed scale, based on characteristic urban morphology types, land uses and extensions are correlated with vegetation cover and surface temperatures in so-called climatic sub-zones, in the municipalities of Peñalolen, Santiago Centro and Cerrillos, that represent different urban locations, natural cover and socioeconomic variables across the city. The article concludes that there are areas with adverse conditions for the population and configurations that highlight the heterogeneity and diversity of these municipalities.
\end{abstract}

KEY WORDS | Urban environment, environment quality, urban sustainability. 


\section{Introducción: clima y medio ambiente urbano}

El variado y diverso mosaico de paisajes que constituyen el medio ambiente urbano se explica por un conjunto muy numeroso de relaciones entre componentes naturales y sociales que se establecen al interior de las ciudades. Los principales elementos que constituyen el medio ambiente natural urbano, tales como el aire, el agua o los suelos, son modificados substancialmente por la construcción de las ciudades. Dentro de la ciudad es difícil separar los elementos aportados por la naturaleza de aquellos construidos socialmente, por lo que las relaciones ambientales están exigiendo nuevos enfoques, como la Ecología Política, que plantean justamente la necesidad de que los problemas ambientales urbanos sean abordados con conceptos integradores. La climatología, la hidrología y la ecología urbana están intentando dar cuenta de esas transformaciones y durante las últimas décadas se ha avanzado en el establecimiento de categorías de análisis cuyos objetos representan productos integrados de la naturaleza y la sociedad, pudiéndose hablar, por ejemplo, de socioclimas o de ciclos sociohidrológicos (Pelling, 2003; Budds, 2009; Trawick, 2003).

Por otro lado, parece haber acuerdo sobre las definiciones de sustentabilidad que pretenden combinar el logro de objetivos económicos, sociales y ambientales en el desarrollo de las ciudades. Los aspectos económicos y sociales son objeto de evaluaciones que preceden las decisiones sobre los espacios urbanos, existiendo conceptos y metodologías que son aplicados con regularidad por organismos públicos y privados. No sucede lo mismo con los componentes ambientales debido a que existen diversas dificultades para realizar evaluaciones ambientales de los planes territoriales urbanos, destacando en primer lugar la ausencia de información que dé cuenta de los efectos de la urbanización sobre la calidad ambiental de las ciudades y de los componentes ambientales sobre la calidad de vida de sus habitantes. La ciudad es un sistema ambiental de infinita complejidad y los datos de que se dispone - por ejemplo, de los climas urbanos como representación de las condiciones atmosféricas y la calidad del aire- carecen de significados espaciales, no constituyen series temporales valiosas e implican generalizaciones que no consideran debidamente la escala de los problemas que representan.

Los climas urbanos no corresponden sólo a las características promedio que adoptan las variables físicas o químicas que presenta el aire al sobrevolar los espacios urbanos. A microescala, cada objeto del paisaje urbano genera especiales flujos e intercambios de materia y energía entre la atmósfera, los suelos, la vegetación, las calles, las casas, los edificios, las industrias, los parques, etc. Los cambios de los usos de los suelos agrícolas o forestales y de las coberturas naturales a usos urbanos generan importantes transformaciones sobre las temperaturas, presión atmosférica, precipitaciones, humedad y vientos, además de la presencia de aerosoles y gases que la contaminan. La urbanización es uno de los principales factores de incremento de la temperatura a escala local (Oke, 1987) y el control y manejo de los climas urbanos es una nueva tarea encomendada a la planificación y gestión ambiental de las ciudades, especialmente bajo los actuales escenarios de cambio climático. 
A escala urbana, aparecen los climas de los doseles o canopias urbanas (urban canopy climates) (Oke, 1987), que no sólo representan las capas atmosféricas que se ubican por debajo de las más altas edificaciones, sino también aquellas causadas por las intervenciones urbanas propiamente tales, que alteran la naturaleza y atributos del aire, como la geometría de calles y edificaciones, materiales y color de las construcciones y el factor de apertura a la insolación directa (sky view factor).

A escala global, la elevación sistemática de las temperaturas, la ocurrencia de ondas de frío y calor, así como los desastres naturales exacerbados por los cambios climáticos (especialmente las inundaciones, derrumbes y avalanchas), afectan severa y cada vez más frecuentemente a las ciudades, al acoplarse a los cambios de micro y mesoescala. En esta última escala espacial se encuentran los que se conocen como climas de los niveles límites (boundary layers climates) (Oke, 1987), cuya caracterización ha sido abordada comparando las diferencias climáticas observadas entre las áreas rurales y urbanas, destacando como objeto especial de análisis las islas de calor urbano (Oke, 1987, 2004). Las islas de humedad y de ventilación son otras formas típicas de los climas urbanos, causados por la sustitución de la vegetación, suelos húmedos y humedales (lo que elimina la evapotranspiración) y por el aumento de los coeficientes de rugosidad, asociados a la pérdida de velocidad y encauzamiento artificial de las brisas y vientos cuando cruzan las ciudades.

La totalidad de las metrópolis y ciudades chilenas han experimentado un acelerado proceso de crecimiento espacial durante las últimas décadas, que ha significado sustituir usos y coberturas de suelos naturales y agrícolas por superficies urbanas, lo que ha derivado en la conformación de islas de calor, humedad y ventilación, así como en elevadas concentraciones de contaminantes atmosféricos, cuya cantidad y especificidad depende de factores geográficos, climáticos y de la presencia de fuentes productoras de gases y sustancias químicas que alteran la composición del aire. Entre los factores geográficos cabe considerar que las ciudades chilenas se ubican al interior de cuencas hidrográficas que actúan como sistemas orográficos semicerrados que dificultan la circulación y ventilación del aire, o bien lo dirigen especialmente a lo largo de corredores correspondientes a ejes fluviales (ríos, esteros y quebradas). Chile se extiende en su gran mayoría en territorios que están bajo la influencia semipermanente del Anticiclón del Pacífico Sur, un centro de altas presiones en que el aire desciende desde las capas altas de la atmósfera, generando inversiones térmicas de subsidencia, por las cuales las temperaturas aumentan antes que disminuir con la altura debido a la compresión del aire. Las capas de inversión térmica impiden la elevación de las masas de aire contaminadas, que quedan atrapadas entre la superficie y los primeros niveles de altura. En el caso de las ciudades costeras, las inversiones de subsidencia son fortalecidas por inversiones de radiación provocadas por las bajas temperaturas de las aguas subantárticas transportadas por la Corriente de Humboldt, mientras que en las áreas más deprimidas de las cuencas hidrográficas interiores, el aire se estabiliza aún más debido al enfriamiento del suelo durante el otoño e invierno. Las altas presiones explican también el predominio de una alta insolación, necesaria para la ocurrencia de contaminación fotoquímica o por ozono. 
La totalidad de las ciudades chilenas están sometidas a episodios de inversiones térmicas que tornan altamente vulnerables sus condiciones atmosféricas, por lo que la planificación ambiental urbana debe controlar especialmente el crecimiento de las fuentes de contaminación y la generación de áreas cálidas hacia las cuales se dirijan las masas de aire contaminadas, como sucede con las islas de calor, o bien el establecimiento de construcciones que reduzcan la ventilación al interior de la ciudad, como ocurre con edificios de altura que obstaculizan el desplazamiento del aire.

Dentro de las fuentes actuales más relevantes de contaminación atmosférica en las ciudades chilenas se encuentran los vehículos, las industrias y el consumo de leña. Todas ellas aumentan su contribución a la contaminación dependiendo del consumo de combustible y, por ello, su control se contrapone con el crecimiento de las tasas de automovilización, generación de barrios industriales e instalación de chimeneas domésticas. Por el contrario, la ciudad compacta y los sistemas de transporte público, la disminución de las emisiones de las fábricas y los sistemas de calefacción no contaminantes, son acciones que se deben emprender junto con el aumento de las áreas verdes que son capaces de filtrar y limpiar las masas de aire y reciclar parte de los contaminantes.

El rol de la vegetación sobre el medio ambiente urbano es bastante más amplio y benéfico, puesto que controla el desarrollo de las islas de calor urbanas, al brindar sombra y consumir calor latente mediante el proceso de evapotranspiración. Las áreas verdes urbanas constituyen islas frías, a partir de las cuales se originan "brisas de parque" o flujos de aire limpio y fresco, cuya potencia depende del tamaño y complejidad de las superficies vegetadas y cuya capacidad de penetración hacia las áreas urbanas se desarrolla a lo largo de calles arboladas interconectadas y que no son bloqueados por edificaciones. Los parques, plazas y jardines urbanos cumplen importantes roles y brindan significativos servicios ambientales, en particular en las ciudades más contaminadas, pero para ello deben formar parte de sistemas espaciales articulados que los vinculan entre sí y con los cinturones verdes que se establezcan en los límites de las ciudades o que resultan de la permanencia de campos agrícolas, terrenos forestados o áreas de conservación de la naturaleza.

En el caso de Santiago, la expansión urbana de cerca de 1.000 ha anuales en promedio para las últimas décadas ha ocupado miles de hectáreas de tierras agrícolas, muchas de ellas de óptima calidad, o bien cubiertas por remanentes de bosques y matorrales nativos, lechos fluviales, humedales, etc., para instalar áreas residenciales de alta densidad, especialmente en las periferias norte, poniente y sur, y urbanizaciones de baja densidad sobre terrenos anteriormente cubiertos por vegetación natural densa y dispersa, especialmente en los bordes del sector oriente y sobre los piedemontes andinos (Romero, 2004; Vásquez y Romero, 2007; Escobedo et al., 2006; Romero y Vásquez, 2005). Resulta paradójico que la vegetación agrícola y natural sea destruida y con posterioridad se intente inútilmente restaurar la urbanización a un alto costo, como parte de los espacios públicos y privados de la ciudad (Platt, 2006).

En consecuencia, las áreas urbanas suelen presentar diferencias climáticas considerables respecto a áreas rurales (Pérez Gonzales et al., 2003; Cuadrat, 1993). Las islas de calor urbano pueden explicar las temperaturas entre 2 y $8{ }^{\circ} \mathrm{C}$ más elevadas 
de los centros urbanos respecto a las periferias rurales (Oke, 1987). La intensidad de la isla de calor aumenta en el transcurso del día, partiendo desde la salida del sol hasta un máximo que se registra unas pocas horas después de la puesta del sol. Generalmente durante el día la intensidad del calor urbano es bastante débil, y a veces negativa (una isla fría o áreas de hundimiento de calor) en algunas partes de la ciudad como consecuencia de que los edificios altos proveen de sombras extensas, así como debido a los materiales de construcción (Peña, 2008; Voogt y Oke, 2003).

Sin embargo, al mediodía, se comienzan a desarrollar microislas de calor urbano sobre las áreas construidas más notables e impermeabilizadas, tales como los aeropuertos y zonas industriales, que alcanzan las temperaturas más elevadas en el verano. En la noche, estas islas de calor se consolidan espacialmente sobre las zonas industriales, aeropuertos y áreas residenciales de alta densidad. Una diferencia promedio de $2{ }^{\circ} \mathrm{C}$ se registra entre las temperaturas del aire de las áreas residenciales de alta y baja densidad como consecuencia de los diferentes porcentajes de áreas verdes e impermeabilizadas (Pauleit y Duhme, 2000; Wihtford et al., 2001; Kardinal Jusuf et al., 2007).

Existen importantes relaciones espaciales entre los usos y cubiertas de la tierra y las temperaturas del aire de la ciudad y su evolución diaria. Respecto a lo primero, es posible correlacionar las temperaturas de emisión de los objetos que constituyen las superficies urbanizadas, también llamadas temperaturas superficiales, con la temperatura del aire, que se registran a una altura sobre $1,5 \mathrm{~m}$. Las primeras se obtienen empleando las informaciones de radiación infrarroja proporcionada por las imágenes de satélite y, las segundas, por termómetros instalados en diferentes sectores de la ciudad, que representan a diferentes posiciones geográficas y usos del suelo.

En cuanto a la distribución espacial de las islas de calor urbano y aun dentro del concepto de dosel urbano, Lowry (1977) sostiene que el estudio de las diferencias entre zonas urbanas y rurales es poco efectivo para identificar los efectos de la urbanización sobre el clima, por lo que propone clasificar y analizar subzonas urbanas integrando el paisaje local y las características específicas del lugar. Withford et al. (2001) establecieron una diferencia de hasta $7{ }^{\circ} \mathrm{C}$ de temperatura de emisión superficial entre zonas con $15 \%$ y $50 \%$ de área verde. Por otro lado, Kardinal Jusuf et al. (2007) compararon para Singapur los usos y coberturas de suelo con las temperaturas de emisión superficial para el mediodía, y con las temperaturas atmosféricas para la noche. Al mediodía obtuvo en promedio una diferencia de 4,21 ${ }^{\circ} \mathrm{C}$ entre las estructuras urbanas y las áreas vegetadas; en cuanto a las diferencias entre los usos dentro de la ciudad, la temperatura más alta la observó en la zona industrial $\left(39,69^{\circ} \mathrm{C}\right)$ y la más baja en los parques urbanos $\left(34,29^{\circ} \mathrm{C}\right)$.

A escala de los niveles límites, Pérez Gonzales et al. (2003) indican que es necesario estudiar la radiación de las edificaciones, el tipo de material utilizado en ellas y la variación que implica el arbolado urbano (Grimmond y Oke, 1998; Correa et al., 2003; Shashua-Bar et al., 2009). Por otro lado, se encuentran autores que destacan la relación entre la sustitución de coberturas naturales por superficies urbanas impermeables que modifican el balance hídrico y por ende la intensidad de 
radiación (Pauleit y Duhme, 2000; Withford et al., 2001). Además, es importante considerar las dinámicas de circulación del aire producto de la intercepción y obstaculización de los flujos originales causadas por la geometría urbana (Lindberg et al., 2003; Tablada et al., 2009).

El aumento en la demanda de energía en las áreas urbanas, causado por la actividad industrial, el uso de vehículos (tamaño del parque automotriz), las calefacciones y otras actividades humanas, favorecen el aumento de la contaminación ambiental, causada por las emisiones de material particulado de diferentes tamaños y de gases como el Dióxido de Carbono $\left(\mathrm{CO}_{2}\right)$, Óxidos de Nitrógeno $\left(\mathrm{NO}_{x}\right)$, Dióxido de Asufre $\left(\mathrm{SO}_{2}\right)$ y Ozono $\left(\mathrm{O}_{3}\right)$, además de Compuestos Orgánicos Volátiles (COV), entre muchos otros. El ozono troposférico es un contaminante secundario que consiste en una transformación fotoquímica de los $\mathrm{NO}_{x}$ bajo condiciones de alta insolación, por lo que sus altas concentraciones se localizan especialmente en ciudades de latitudes subtroplicales donde predominan las altas presiones y los cielos despejados. La Isla de Calor Urbano genera un tiro convectivo (ascenso de aire cálido) sobre las áreas más densamente urbanizadas de la ciudad, originando zonas de bajas presiones atmosféricas relativas, que controlan la circulación local de aire proveniente de áreas más frías como la periferia rural. Con ello, se produce un desplazamiento de masas de aire contaminado, que pueden arribar a otros sectores de la ciudad o a áreas rurales situadas a decenas de kilómetros de ésta, contaminando lugares que carecen de fuentes fijas o móviles en su cercanía (Crutzen, 2004; Oke, 1987).

La ciudad de Santiago ha registrado altas concentraciones de contaminantes atmosféricos desde que se recopilan sistemáticamente sus datos, desde fines de la década de 1970. Dichos datos informan sobre el comportamiento del polvo en suspensión, micropartículas y gases como $\mathrm{CO}, \mathrm{SO}_{2}$ y $\mathrm{NO}_{\mathrm{x}}$, adquiridos primero en forma manual como parte de una red de vigilancia epidemiológica y posteriormente, desde 1986, mediante la llamada Red de Monitoreo de la Contaminación Atmosférica de la Región Metropolitana (Red MACAM), por la cual cinco estaciones fueron instaladas en el centro histórico de la ciudad, en el Parque O'Higgins ubicado al Sur del centro, en el campus Norte de la Universidad de Chile, localizado al Norte del centro, en Avenida Seminario con Providencia en el Centro Oriente y en el Estadio Las Condes, localizado en el Oriente de la ciudad. Con posterioridad, se modernizaron los equipos de mediciones, desactivaron tres de los puntos (Centro, Centro Norte y Centro Oriente) y aumentó el total a ocho estaciones, que son las actuales y que incluyeron tres lugares en el sector poniente y una estación en el sector Sur Oriente (Figura 1). El número de estaciones de monitoreo para una ciudad que supera las 75.000 ha es claramente insuficiente. Sobre la base de los datos recopilados se implementaron índices de calidad del aire, que primeramente consideraban la totalidad de los parámetros y posteriormente se simplificaron, para basarse sólo en las micropartículas. Para el conjunto de contaminantes se han dictado normas primarias de calidad que indican las concentraciones sobre las cuales se producen daños sobre la salud y se ha elaborado un plan 
de acciones que se desencadenan según sean los umbrales en que son superadas dichas normas, incluyendo restricciones sobre la circulación de vehículos y paralización de industrias contaminantes.

Tal como se ha señalado, el PM10 es el contaminante que determina el estado de la contaminación atmosférica de la ciudad y sus concentraciones han sido correlacionadas con la ocurrencia de enfermedades y muertes, causadas especialmente por problemas respiratorios y cardiovasculares (Ostro et al., 1995). El Material Particulado (PM10), es definido como una mezcla heterogénea de sustancias químicas y partículas de tamaño menor a 10 micrones, totalmente respirables a la que regularmente está expuesta la población, incluyendo sustancias directamente emitidas al aire, tales como hollín de diesel, polvo proveniente de caminos, partículas inherentes a la quema de madera o procesos industriales (Ostro, 1998). No obstante el volumen de las concentraciones de micropartículas, se trata de una mínima parte de la cantidad total de los contaminantes que se acumulan en la atmósfera de Santiago, siendo superado en forma muy amplia, especialmente por el $\mathrm{CO}, \mathrm{COV} \mathrm{y} \mathrm{O}_{3}$. Sin embargo, las medidas que se adoptan para intentar controlar la contaminación, no incluyen actuaciones directas sobre las fuentes de estos últimos. Por otro lado, existe una relevante geografía de la contaminación atmosférica por la cual las partículas se concentran en el Poniente, los gases en el Centro y el ozono $\left(\mathrm{O}_{3}\right)$ en el Oriente de la ciudad. Desde el punto de vista temporal, las mayores concentraciones se registran en otoño e invierno, excepción hecha del $\mathrm{O}_{3}$, que lo hace en primavera y verano. Si se adoptaran medidas destinadas a controlar el ozono, la ciudad estaría todo el año bajo niveles críticos.

La relación entre climas urbanos y contaminación atmosférica es aún poco conocida en Santiago. Ello se debe en parte a que los estudios sobre contaminación se han concentrado en el comportamiento físico y químico de la atmósfera y de sus fuentes fijas y móviles, antes que en comprender su asociación con las estructuras y funciones urbanas, con el crecimiento de las ciudades y con los cambios en los usos y coberturas de los suelos. La contaminación no ha sido considerada un problema ambiental asociado a las condiciones urbanas, en parte debido a los enfoques disciplinarios prevalecientes y en parte como consecuencia de la información disponible. La red de estaciones de monitoreo de la contaminación atmosférica de que dispone la ciudad ha sido localizada para representar la condición de grandes áreas, determinando en forma arbitraria un área circular de influencia en torno a las estaciones, que desconoce completamente los tipos de usos y coberturas de suelos que conforman las áreas urbanas y la localización de fuentes móviles o fijas de contaminantes específicos. Se trata de conocer aproximadamente la llamada contaminación de background o concentración de contaminantes sobre secciones que más bien corresponden a puntos cardinales de ciudad antes que a áreas o corredores asociados a la concentración de contaminantes en torno a las principales fuentes emisoras. Buzzelli (2009) demuestra que una ciudad puede clasificarse como escasamente contaminada, o bien congratularse de haber reducido sus concentraciones, al no tener en cuenta que ésta puede estar aumentando severamente en torno a las calles de mayor congestión de tráfico o alrededor de fuentes fijas. Por ello, se propone aumentar la resolución espacial de las mediciones y de los 
sistemas de monitoreo, así como considerar el poder explicativo de relaciones estadísticas significativas que asocien los usos y coberturas de los suelos urbanos, las distancias a las vías de circulación más congestionadas, la presencia de áreas verdes, la geometría de las edificaciones y diversos otros atributos urbanos que permitan construir modelos espaciales de la contaminación atmosférica y sus efectos, por ejemplo, sobre la salud de la población socialmente más vulnerable.

FIGURA 1 | Localización Estaciones meteorológicas, Santiago de Chile

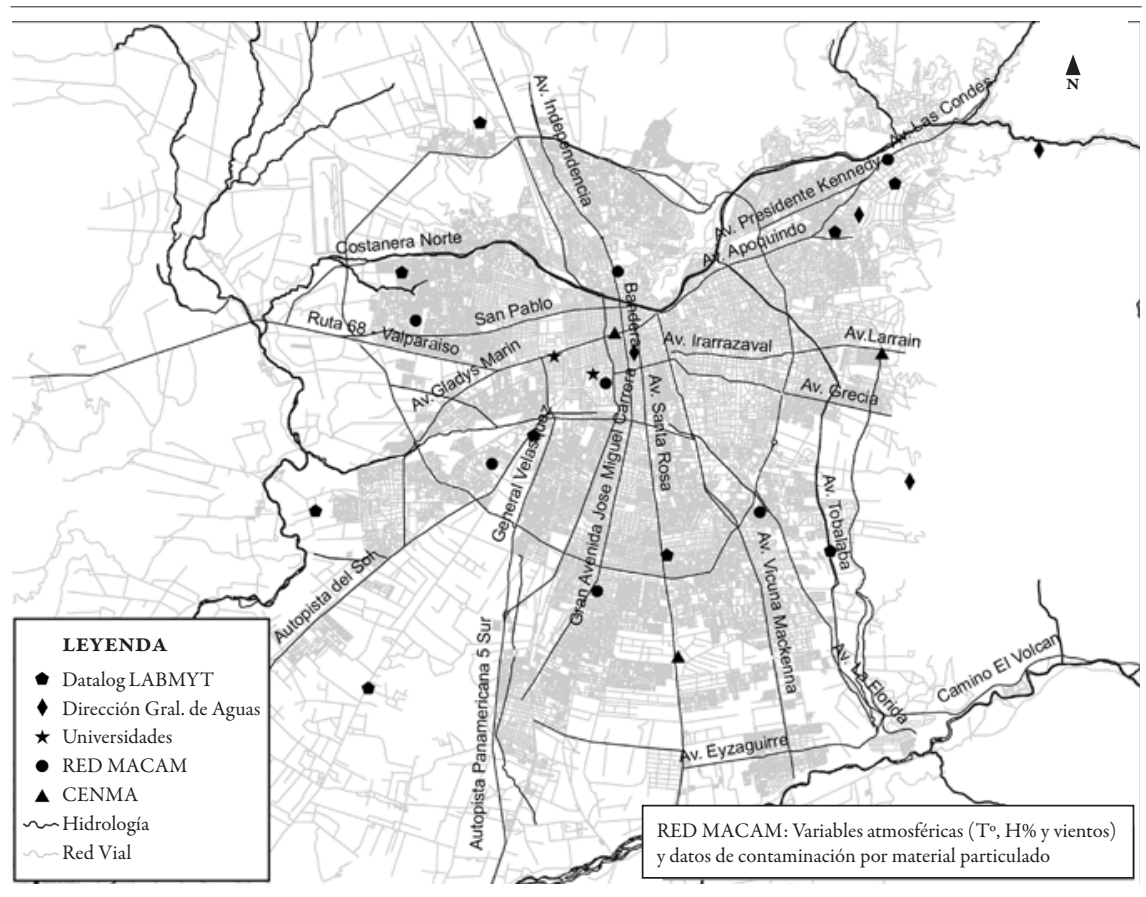

FUENTE ELABORACIÓN PROPIA.

Con el objetivo similar de aumentar la resolución espacial de la investigación de los climas urbanos, en este trabajo se han analizado los datos meteorológicos recopilados por la Red MACAM, lo que no se había realizado hasta ahora. Para ello fue necesario calibrar los datos de temperaturas del aire y de vientos. Al mismo tiempo, se procedió a construir series espaciales que adicionaron los datos de temperatura del aire, que junto a otros indicadores meteorológicos han estado siendo almacenados por sensores instalados por el Laboratorio de Medio Ambiente y Territorio del Departamento de Geografía de la Universidad de Chile en áreas urbanas seleccionadas, por corresponder a estructuras morfológicas claramente heterogéneas y que están repartidas a lo largo y ancho de la ciudad (Figura 1). Dichas zonas habían sido diferenciadas sobre la base de fotointerpretaciones que relacionaron las temperaturas de emisión superficial con los usos y coberturas de los suelos, y que fueron corroboradas mediante transectos móviles 
practicados en días de verano e invierno de los años 2007, 2008 y 2009. Stewart y Oke (2009) propusieron, sobre la base de una extensa revisión bibliográfica de las investigaciones realizadas sobre ICU entre los años 1950 y 2007, que era necesario que dichas zonas homogéneas fuesen reconocidas como Zonas Climáticas Termales (TCZ). En un primer nivel de clasificación consideraron el paisaje urbano general en cuatro clases (urbano, natural, agrícola y mixto), para después dividir cada uno de estos tipos en subclases, alcanzando un total de veinte zonas climáticas termales. Los criterios para la definición de las subclases incluyeron el total de superficie impermeabilizada, la estructura urbana considerando el Factor de Visibilidad del Cielo, la clasificación de rugosidad de Davenport et al. (2000) y la temperatura de emisión o flujo de calor antropogénico.

Considerando que las variaciones de los factores explicativos de los climas urbanos y sus relaciones con la contaminación atmosférica alcanzan grandes diferencias entre los diversos sectores de la ciudad, pareció importante aumentar las unidades espaciales de análisis, seleccionando tres comunas que presentaran significativas diferencias en cuanto a su localización en la cuenca de Santiago (Figura 2), ubicándose al Oriente (Peñalolén), Poniente (Cerrillos) y Centro histórico. Dada la segregación social prevaleciente entre las distintas comunas que conforman Santiago, las áreas seleccionadas responden a distintos patrones de localización de los grupos socioeconómicos presentes en la ciudad, lo que es examinado también en este trabajo.

\section{FIGURA 2 | Área de estudio}

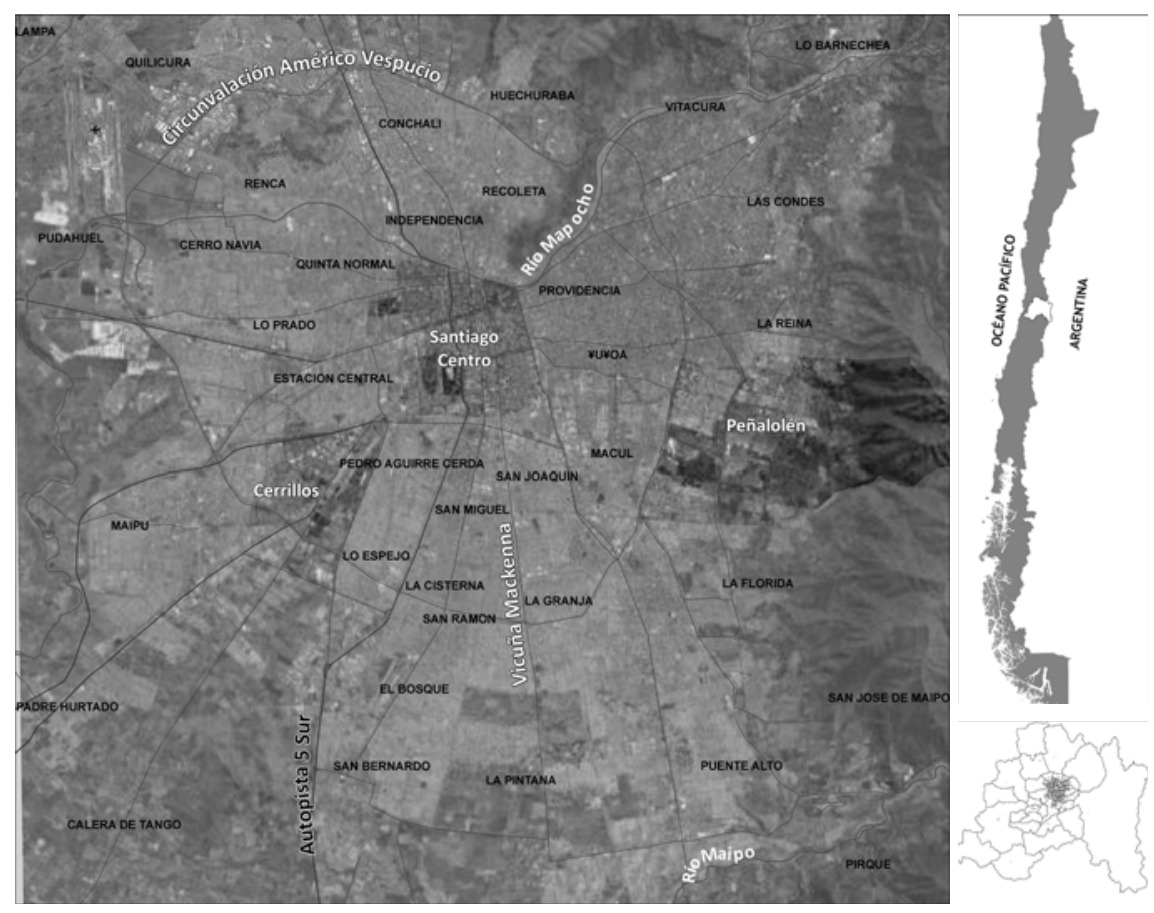

FUENTE ELABORACIÓN PROPIA. 


\section{Metodología}

Se analizaron los datos de concentración de material particulado, temperaturas del aire y mediciones de dirección y velocidad de los vientos registrados por la Red MACAM, operado por la Secretaría Regional Ministerial de Salud y los datos de temperatura del aire recopilados por el Laboratorio de Medio Ambiente y Territorio del Departamento de Geografía de la Universidad de Chile. Para el estudio de las concentraciones de material particulado se seleccionaron aquellos días en que el promedio diario superó la norma de calidad establecida por CONAMA y que corresponde a $150 \mu \mathrm{g} / \mathrm{m}^{3}$. Para tales días seleccionados se examinaron los datos de temperatura del aire y vientos registrados por las mismas estaciones. El conjunto de las estaciones de monitoreo fueron localizadas como puntos digitalizados mediante el Sistema de Información Geográfica (SIG) ArcGis 9.3, creando un nivel (shape) mediante ArcCatalog, al cual se anexó una tabla de atributos con los datos diarios promedios, máximos y mínimos de temperatura y contaminación. Para la representación espacial de las informaciones se empleó el método de interpolación Kriging (ordinario), el cual ha sido utilizado anteriormente en estudios de este tipo de manera satisfactoria (Villatoro et al., 2008; Moral et al., 2006).

Las variables ambientales analizadas corresponden a Coberturas Vegetales y Temperaturas de Emisión Superficial, registradas en las áreas residenciales de las comunas seleccionadas. Ambas fueron obtenidas a partir del procesamiento digital de la imagen satelital ASTER (Advanced Spaceborne Thermal Emission and Reflection Radiometer) de fecha 2 de diciembre del año 2008, captada a las 14:51 horas. Los procesamientos digitales de las imágenes fueron desarrollados en los sistemas de información geográfica Envi 4.5 e Idrisi Andes.

La Cobertura Vegetal se obtuvo a partir de una Clasificación Supervisada a escala espacial de subpixeles empleando el programa Idrisi Andes, para lo cual se utilizó un clasificador blando, que permite destinar estas unidades espaciales a alguna de las siguientes clases definidas por sus porcentajes de cobertura vegetal: 0 - 25\%; 25 - 50\%; 50 - 75\% y 75 - 100\%. La Temperatura de Emisión Superficial se obtuvo mediante la utilización del módulo Emissivity Normalization contenido en el SIG Envi 4.5.

En las comunas seleccionadas, se realizó una identificación de Zonas Climáticas Termales, para lo cual se ha elaborado una tipología (Cuadro 1) que corresponde a una adaptación de las definidas por Stewart and Oke (2009), mediante una fotointerpretación sobre imágenes QuickBird escala 1:5000 de los años 2008 y 2009, proporcionadas por el software Google Earth, con resolución espacial de 2,44 metros en las bandas multiespectrales (azul, verde, rojo e infrarrojo cercano). Las zonas identificadas se asociaron a variables ambientales y a la composición socioeconómica de la población. Adicionalmente, se llevó a cabo un análisis a nivel de subzonas climáticas, con la finalidad de demostrar que a medida que se aumenta la escala de análisis aparecen nuevas unidades espaciales, debido a la complejidad y diversidad de los paisajes ambientales urbanos. 
CUADRO 1 | Tipología zonas climáticas urbanas

\begin{tabular}{|c|c|c|}
\hline $\begin{array}{c}\text { Tipología } \\
\text { Stewart \& OKe } \\
(2009)\end{array}$ & ADAPTACIÓN & CARACTERÍsticas \\
\hline \multirow[t]{2}{*}{ COMPACt LOWRISE } & Urbanización Alta Densidad & $\begin{array}{l}\text { Áreas continuas de viviendas, con escasos o nulos } \\
\text { espacios entre cada estructura, entre } 60 \text { y } 80 \% \text { de } \\
\text { superficie impermeabilizada. }\end{array}$ \\
\hline & Urbanización Media Densidad & $\begin{array}{l}\text { Viviendas de disposición irregular entre } 40 \% \text { y } 60 \% \text { de } \\
\text { superficie impermeable. }\end{array}$ \\
\hline Open Set Lowrise & Urbanización Baja Densidad & $\begin{array}{l}\text { Áreas con un porcentaje de impermeabilización que } \\
\text { oscila entre } 20 \text { y } 40 \% \text {. }\end{array}$ \\
\hline $\begin{array}{l}\text { OPEN SET MIDRISE - } \\
\text { BLOCKS }\end{array}$ & Bloques de Viviendas & $\begin{array}{l}\text { Edificación de altura baja a media (entre } 3 \text { y } 7 \text { pisos), } \\
\text { con superficies impermeables que oscilan entre } 25 \% \\
\text { y } 50 \% \text {. }\end{array}$ \\
\hline Regular Housing & Viviendas Uniformes o Regulares & $\begin{array}{l}\text { Viviendas de disposición regular entre } 40 \% \text { y } 60 \% \\
\text { de superficie impermeable. Asociada a condominios } \\
\text { cerrados. }\end{array}$ \\
\hline $\begin{array}{l}\text { LIGHTWEIGHT } \\
\text { LOWRISE }\end{array}$ & Campamentos & $\begin{array}{l}\text { Construcciones de material ligero, asociadas a tomas } \\
\text { de terreno. }\end{array}$ \\
\hline EXTENSIVE LOWRISE & Industrias y Galpones & $\begin{array}{l}\text { Grandes construcciones en superficies sin vegetación } \\
\text { que ocupan la mayor parte del área (Fábricas, Galpones, } \\
\text { Multitiendas y Grandes Supermercados). }\end{array}$ \\
\hline Open Ground & Espacios Abiertos & $\begin{array}{l}\text { Superficies con bajo porcentaje construido. Parques } \\
\text { urbanos, universidades, colegios. }\end{array}$ \\
\hline BARE GRound & Urbano en desuso & $\begin{array}{l}\text { Sitios eriazos y suelos desnudos, sin presencia de } \\
\text { vegetación. }\end{array}$ \\
\hline Moderm Core & Centro Nuevo & $\begin{array}{l}\text { Espacios de alta densidad de construcción con edificios } \\
\text { en altura (sobre } 8 \text { pisos), asociados a procesos de } \\
\text { renovación urbana. }\end{array}$ \\
\hline \multirow[t]{2}{*}{ Old Core } & Centro Antiguo & $\begin{array}{l}\text { Espacios de alta densidad de construcción con edificios } \\
\text { de mediana altura ( } 4 \text { a } 7 \text { pisos). }\end{array}$ \\
\hline & Mixto (Centro antiguo y nuevo) & $\begin{array}{l}\text { Coexisten espacios de alta densidad con construcciones } \\
\text { de baja ( } 1 \text { a } 3 \text { pisos), media y gran altura. }\end{array}$ \\
\hline Sparcely Developed & Asentamiento Disperso & $\begin{array}{l}\text { Áreas residenciales Suburbanas, grandes predios con } \\
\text { muy bajas tasas de construcción y alto porcentaje de } \\
\text { cobertura vegetal (sobre } 75 \% \text { ). }\end{array}$ \\
\hline
\end{tabular}

FUENTE ELABORACIÓN PROPIA.

\section{Análisis de la composición socioeconómica del área de estudio}

Para determinar la composición socioeconómica del área de estudio se utilizó la clasificación propuesta por Adimark (2004). Esta clasificación se basa en un modelo de estimación del nivel socioeconómico de los hogares, cuyo resultado es la identificación de cinco grupos: $\mathrm{ABC} 1$ y $\mathrm{C} 2$, que corresponden a los dos quintiles con más altos ingresos; $\mathrm{C} 3$ que corresponde al quintil con ingresos medios y, finalmente, los sectores más pobres $\mathrm{D}$ y E. 
Cada grupo socioeconómico se define considerando simultáneamente dos variables: el nivel de educación del jefe de hogar (sin estudios, básica incompleta, básica completa, media incompleta, media completa, técnico incompleta, universitaria incompleta o técnico completa, universitaria completa o más) y la tenencia de un conjunto de bienes (ducha, TV color, refrigerador, lavadora, calentador de agua, horno microondas, automóvil, TV por cable o satelital, Computador Personal e Internet). De acuerdo al modelo, estas variables se relacionan con el nivel cultural y con el stock de riquezas acumulado por un grupo familiar, correspondiendo al concepto tradicional de nivel socioeconómico. La información utilizada es obtenida del Censo de Población y Vivienda del año 2002 y ha sido procesada a través del sistema computacional REDATAM + G4. La unidad de análisis corresponde a las manzanas censales (unidad menor de la división político-administrativa).

\section{Resultados}

Distribución de la contaminación por material particulado y temperatura atmosférica para la ciudad de Santiago

El 11 de mayo fue el día en el cual se presentó el mayor promedio diario del año 2009 en términos de concentración de PM10 en todas las estaciones de monitoreo de la Red MACAM, registrándose valores que variaron entre $80 \mu \mathrm{g} / \mathrm{m}^{3}$ en la estación de Las Condes, en el Oriente de la ciudad, y $260 \mu \mathrm{g} / \mathrm{m}^{3}$ en la estación de Cerro Navia, en el Poniente de Santiago y cuyo máximo horario se obtuvo a las 20 horas. El patrón de distribución espacial de la contaminación por material particulado muestra una división de la ciudad en dos zonas bien diferenciadas, Oriente y Poniente, lo que se relaciona con la presencia de dos grandes zonas termales (Figuras 3 y 4). La zona mayormente contaminada comprendió las comunas de Cerro Navia, Lo Prado y Pudahuel (sector Poniente de la ciudad), sumándose El Bosque y La Cisterna (sector Sur de la ciudad), todas las cuales presentaron altas concentraciones a lo largo del día, pero que al anochecer se elevaron considerablemente. A su vez, en cuanto a la temperatura del aire, se registraron los valores más elevados en el sector Poniente, en las comunas de Pudahuel, Maipú, Estación Central y Lo Prado. Sólo la comuna de Cerrillos registró una mejor calidad del aire. Por el contrario, las comunas del sector Oriente, no sólo presentaron una mucho mejor calidad del aire, sino que también, en el caso de Vitacura, Las Condes y Lo Barnechea, una temperatura inferior en al menos $2^{\circ} \mathrm{C}$ en comparación con el sector Poniente, lo que debería ser suficiente para generar brisas que trasladen la contaminación desde la sección Oriente.

Toda la ciudad de Santiago presentaba esa noche de otoño niveles de contaminación por material particulado que superaban las normas de calidad del aire, superando los $170 \mu \mathrm{g} / \mathrm{m}^{3}$ en el sector Oriente y alcanzando los $400 \mu \mathrm{g} / \mathrm{m}^{3}$ en el sector Poniente. 
FIGURA 3 | Temperatura atmosférica promedio para la ciudad de Santiago

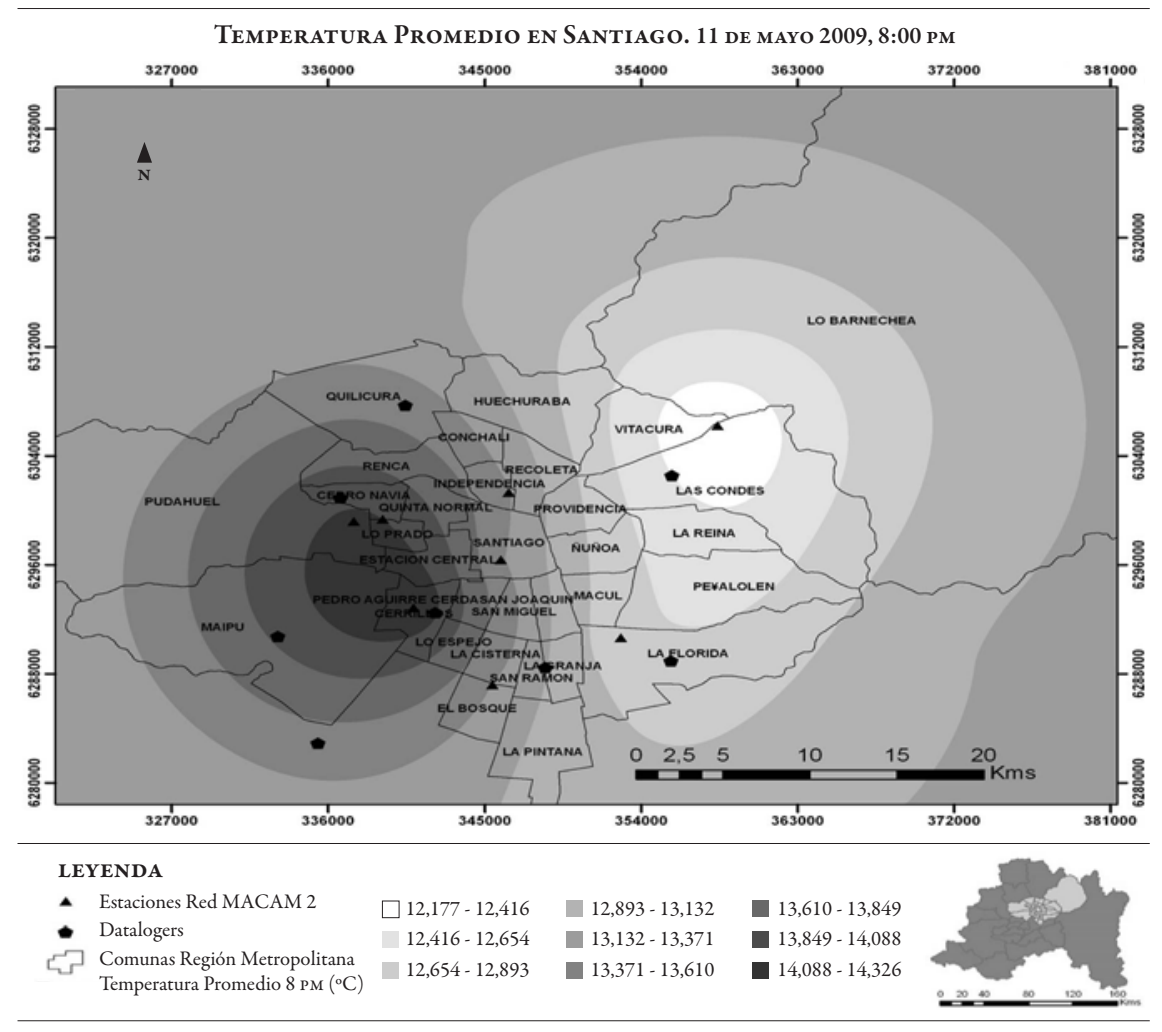

FUENTE ELABORACIÓN PROPIA A PARTIR DE INFORMACIONES PROPORCIONADAS POR LA RED MACAN DE LA SEremi de Salud y el Laboratorio de Medio Ambiente y Territorio del Departamento de Geografía de LA U. DE CHILE.

\section{Zonas climáticas urbanas y ambientales}

La distribución de la temperatura de emisión superficial al interior de las comunas de Cerrillos, Santiago Centro y Peñalolén indica que predominan los valores elevados (entre 37,9 y $40,8^{\circ} \mathrm{C}$ ), debido a que se trata de registros adquiridos en el corazón de la estación de verano. Las altas temperaturas se concentraban en Santiago Centro y eran algo menores en Cerrillos y Peñalolén (Figura 5). Áreas urbanas que registraran temperaturas en el suelo por debajo de $32^{\circ} \mathrm{C}$ eran escasas. También eran excepcionales las áreas con temperaturas superiores a $40,8^{\circ} \mathrm{C}$, que sólo son significativas en la comuna de Cerrillos.

El porcentaje de cobertura vegetal varía considerablemente entre las comunas seleccionadas. Peñalolén registra un predominio de áreas que poseen sobre $50 \%$ de cobertura vegetal y aproximadamente un $10 \%$ de éstas alcanzan porcentajes mayores al 75\%. Las comunas de Cerrillos y Santiago Centro muestran una distribución parecida entre sí, predominando las coberturas entre 25 y $50 \%$, alcanzando un mayor significado los porcentajes menores a $25 \%$, en especial en esta última. 
FIgURA 4 | Contaminación por Material Particulado en la ciudad de Santiago

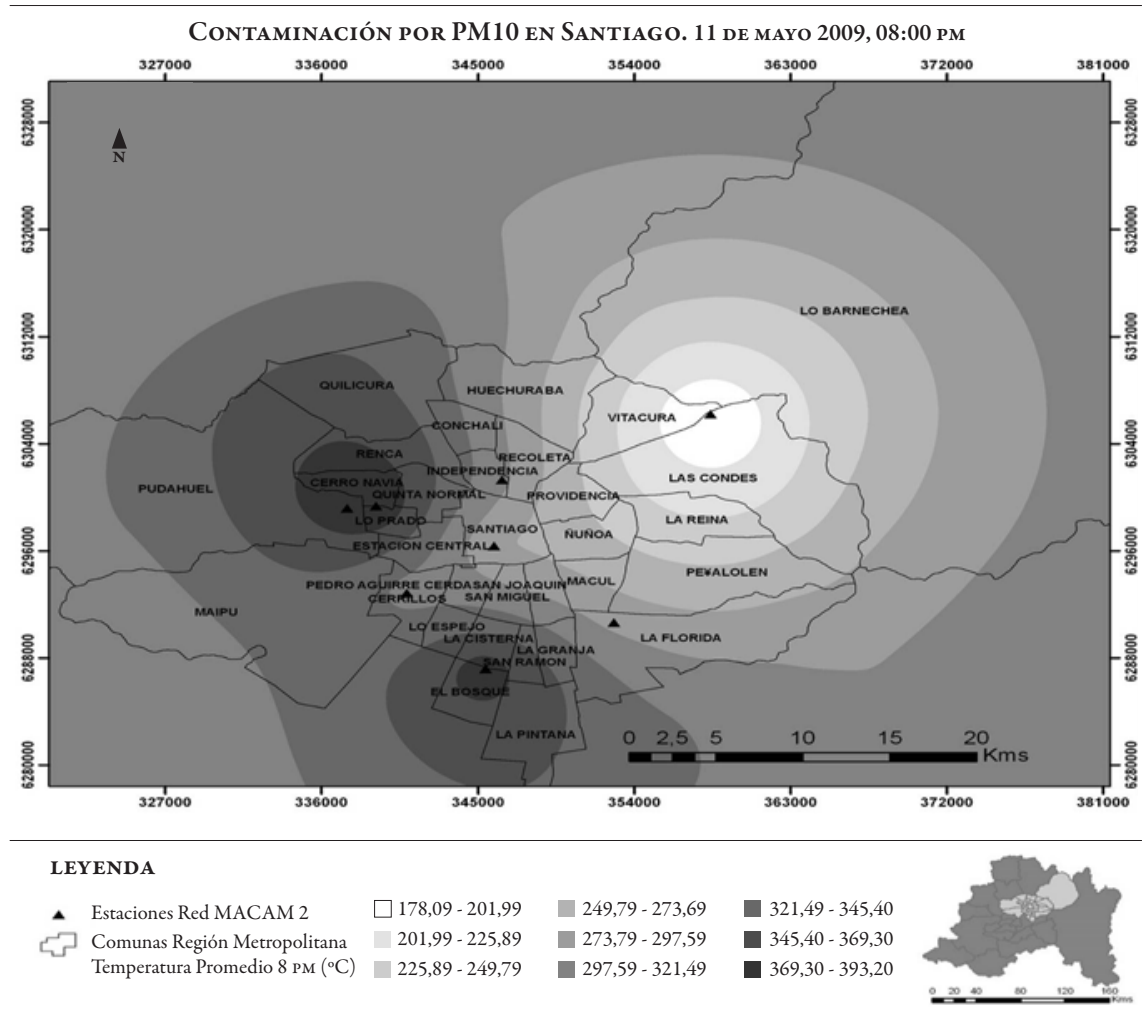

FUENTE ELABORACIÓN PROPIA A PARTIR DE LOS DATOS DE MATERIAL PARTICULADO (MP10) PROPORCIONADOS POR LA REd MACAN de la Seremi de Salud.

FIGURA 5 | Temperatura de emisión superficial (a) y cobertura vegetal (b) en Peñalolén, Cerrillos y Santiago Centro

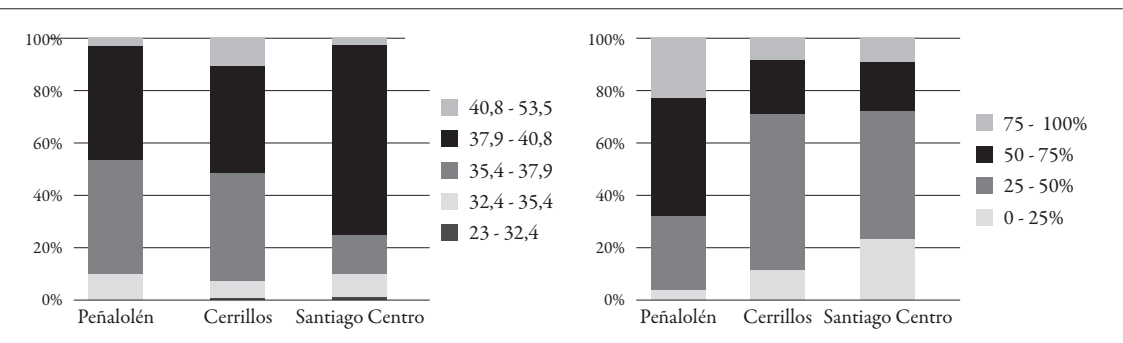

FUENTE ELABORACIÓN PROPIA.

Respecto a la distribución de los usos y coberturas de suelos, la Figura 6a muestra, en primer lugar, las grandes diferencias entre las comunas escogidas, lo que debiera manifestarse también en lo que respecta a las zonas climáticas termales. La comuna de Cerrillos posee una importante superficie ocupada aún por una pista de 
aeropuerto y por industrias y galpones; en Santiago Centro dominan los barrios con edificios antiguos y nuevos, donde se ubican actividades financieras, comerciales y departamentos residenciales. En la comuna de Peñalolén se observa una alta diversidad de usos y coberturas de los suelos, pero predominan las tipologías asociadas a uso residencial de diversas densidades y aún se aprecian remanentes de los usos agrícolas (especialmente viñas) que caracterizaban el paisaje precordillerano hasta hace pocas décadas.

La temperatura de emisión (Figura 6b) también diferencia netamente a las comunas seleccionadas. En Peñalolén se reconoce un archipiélago compuesto predominantemente por islas e islotes comparativamente menos cálidos. Se puede afirmar que se trata de una matriz urbana fresca, interrumpida por islas de calor urbanas. En Santiago Centro, por el contrario, predomina una matriz paisajística que genera islas de calor, interrumpida nítidamente por la presencia de parques, que coinciden con menores temperaturas. Finalmente, en la comuna de Cerrillos existe una división clara entre su sector Oriente, más cálido, y el Poniente más frío. Ello se debe a una matriz urbana diferente, por la cual el primero está conformado por la pista de aterrizaje de un aeropuerto actualmente abandonado, que registra temperaturas sobre $40{ }^{\circ} \mathrm{C}$, así como por galpones e instalaciones industriales que generan igualmente importantes acumulaciones de calor. En el sector Poniente, en cambio, la mezcla de usos urbanos residenciales registra temperaturas más frescas.

La distribución espacial de las temperaturas superficiales se explica en gran medida por la distribución de las coberturas vegetales (Figura 6c). Nuevamente, en Peñalolén predominan las altas coberturas, excepción hecha del sector Norte y una sección del Sur. En Santiago Centro, la vegetación se observa sólo en el Parque O'Higgins y en pequeños paños entre las edificaciones. En Cerrillos, se advierte también en el caso de las temperaturas una gran diferencia entre los sectores Oriente y Poniente.

Respecto a la distribución espacial de las temperaturas de emisión superficial en las zonas termales urbanas, los bloques edificados de vivienda social y las áreas residenciales de densidad media aparecen como los espacios que concentran los valores más elevados, en especial en la comuna de Cerrillos. Por el contrario, el hábitat disperso y las viviendas de baja densidad de la comuna de Peñalolén registran las áreas más frescas. Las diversas zonas termales del centro de Santiago, tales como el centro antiguo y el nuevo, alcanzan elevadas temperaturas.

Las tipologías no residenciales, registran particulares características ambientales que actúan afectando a los usos residenciales adyacentes. Espacialmente, como se observa en la Figura 6, esto es sobre todo evidente en la comuna de Cerrillos, donde las industrias y galpones ocupan una superficie considerable, presentando temperaturas superiores a los $37^{\circ} \mathrm{C}$ y porcentajes de cobertura vegetal que oscilan entre 0 y $25 \%$ y $25 \%$ y $50 \%$, siendo el primero el más significativo. 

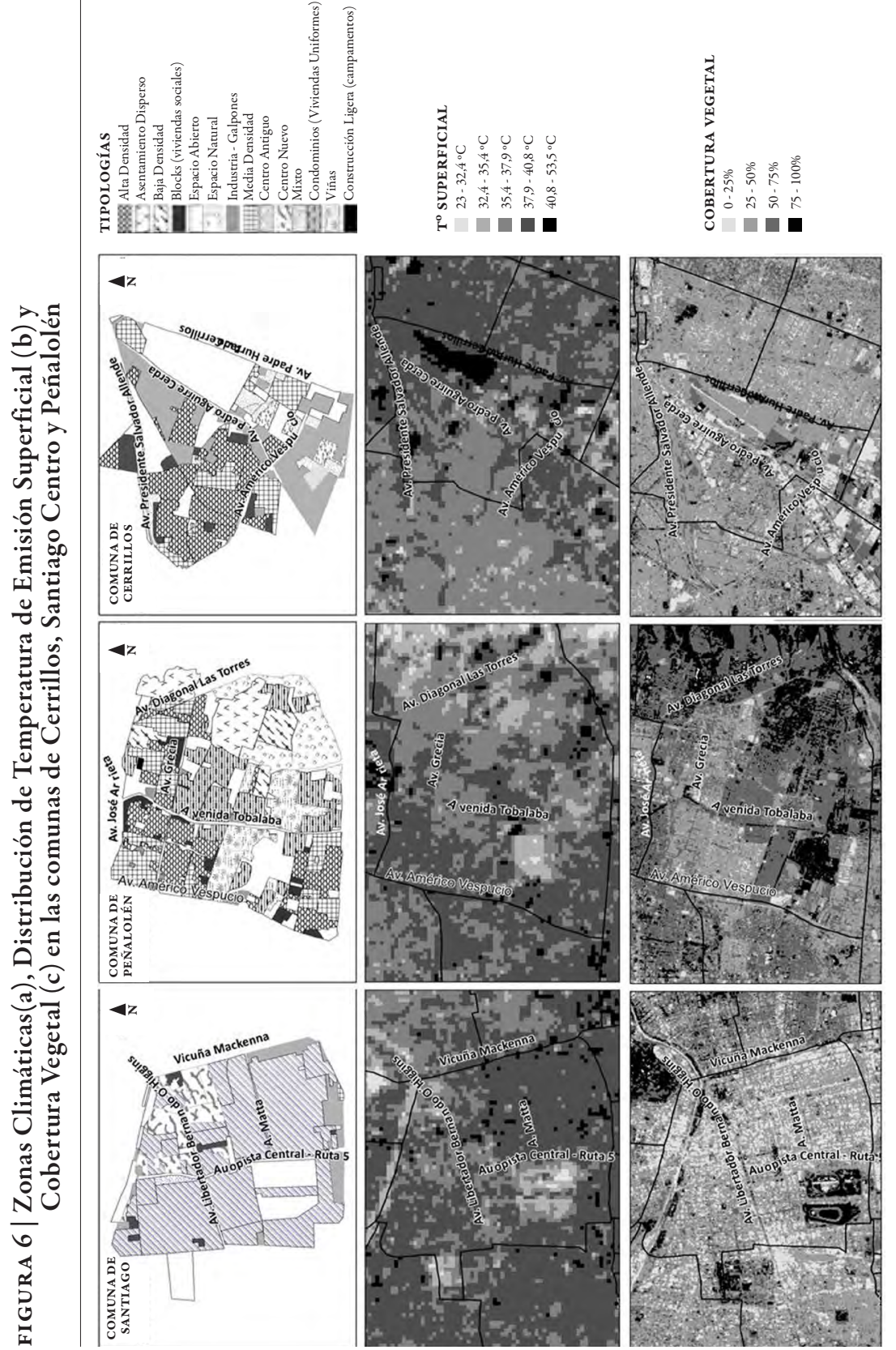


\section{Composición socioeconómica de las zonas climáticas urbanas}

En la Figura 7 se observa la heterogénea composición socioeconómica de la población que reside en las comunas seleccionadas. Destaca, además, el alto porcentaje de superficie ocupada por el grupo de ingresos medios-bajos (D) que se localiza en las comunas de Cerrillos y Peñalolén, y de clase media alta (C2) en Santiago Centro. Los porcentajes más bajos de población pertenecen a los grupos de ingresos altos $(\mathrm{ABC} 1)$ y bajos $(\mathrm{E})$, tendencia que se corresponde con la composición socioeconómica general de la ciudad.

FIGURA 7 | Composición socioeconómica del área de estudio

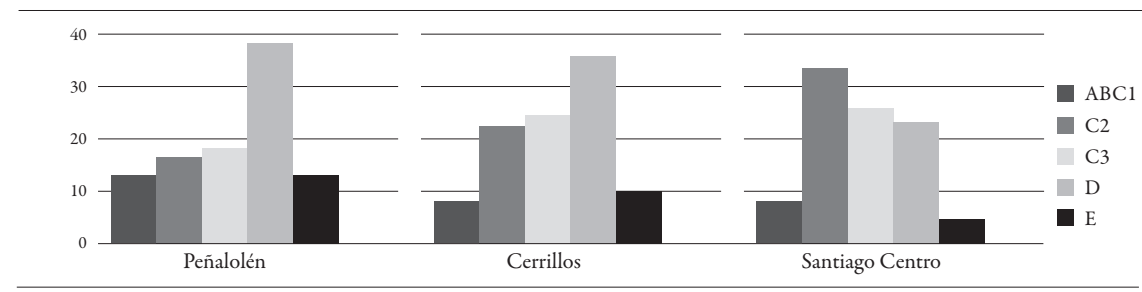

FUENTE ELABORACIÓN PROPIA.

En la Figura 8 es posible apreciar la composición socioeconómica al interior de las zonas climáticas termales. Los grupos de ingresos medios-bajos (D) y bajos (E) se encuentran al interior de las zonas caracterizadas por presentar viviendas de construcción ligera (campamentos que se localizaban sólo en la comuna de Peñalolén) y urbanización de alta densidad, cuyas temperaturas son relativamente altas. Adicionalmente, las zonas de viviendas regulares o condominios cerrados que se encuentran exclusivamente en la comuna de Peñalolén están habitadas mayoritariamente por grupos de ingresos altos $(\mathrm{ABC} 1)$ y medios-altos $(\mathrm{C} 2)$, y registran temperaturas más elevadas de lo que se podría esperar.

En las zonas climáticas termales identificadas en la comuna de Santiago-centro (centro nuevo, centro antiguo y mixto), se observa una importante presencia de población del grupo de ingresos medios-altos (C2) que convive con grupos de ingresos medios (C3) y medios-bajos (D). Sus temperaturas superficiales son también relativamente elevadas.

Respecto a los bloques de viviendas, ubicados en las comunas de Cerrillos y Peñalolén, se observa una composición socioeconómica similar, caracterizada por la mayor presencia de grupos de ingresos medios y medios-bajos. Sus temperaturas son las más elevadas del total considerado, en particular en la comuna de Cerrillos. Esta situación es distinta a la composición socioeconómica de la comuna de Santiago-centro, donde se observa una mayor presencia de población de ingresos altos y medios-altos, por los procesos de renovación urbana que se han señalado.

En cuanto a la urbanización de media densidad, en las tres comunas presenta una composición social semejante, localizando una mayor cantidad de población perteneciente a los grupos de ingresos medios y medios-bajos ( $\mathrm{C} 3 \mathrm{y} \mathrm{D}$, respectivamente) y una menor de los grupos de ingresos bajos (E) y altos (ABC1). 
FIGURA 8 | Composición socioeconómica de las zonas climáticas termales

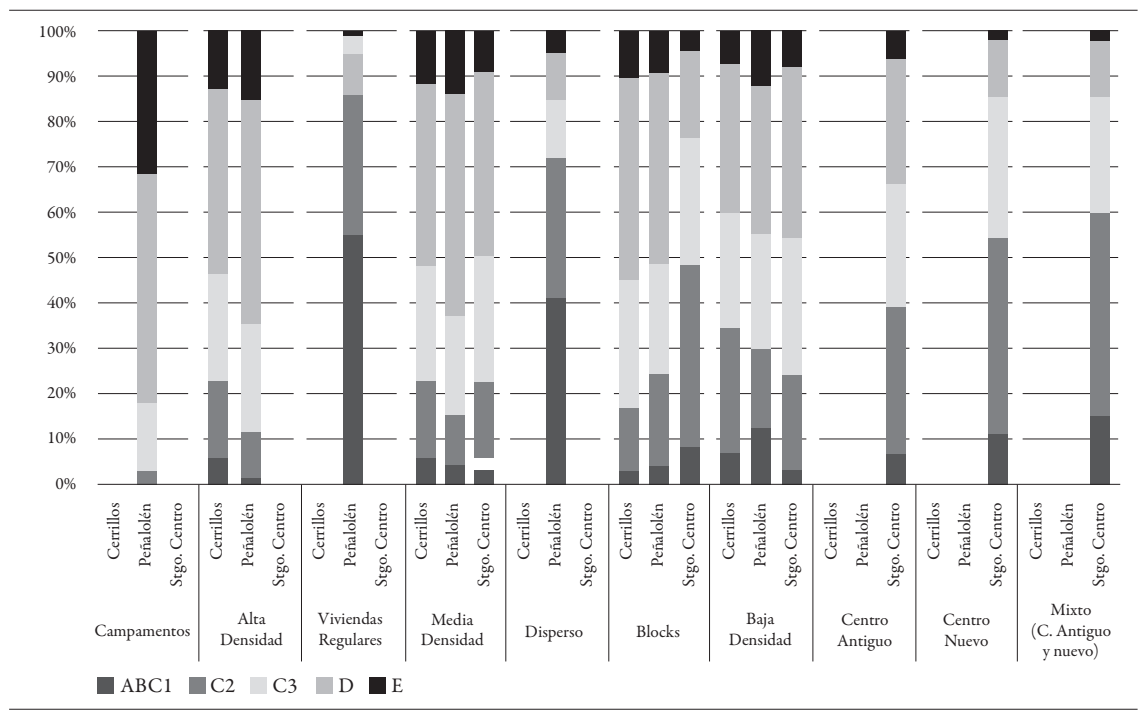

FUENTE ELABORACIÓN PROPIA.

\section{Morfología urbana y subzonas climáticas}

La comuna de Cerrillos se destaca fundamentalmente por presentar subzonas climáticas que corresponden a usos urbanos abandonados, galpones e industrias y áreas residenciales de alta densidad con baja altura (Figura 9). Los sitios urbanos abandonados corresponden, en primer lugar, a terrenos baldíos asociados a baja y media cobertura vegetal, según la matriz del paisaje; segundo, a terrenos en barbecho con alta cobertura vegetal que por lo general colindan con espacios abiertos y, finalmente, al terreno del Aeródromo de Cerrillos que para la fecha de las imágenes se presentaba como un suelo desnudo, debido a un reciente incendio. La presencia de las subzonas de galpones e industrias en la comuna implica áreas que presentan gran cantidad de estacionamientos, donde en ciertos casos no se cuenta prácticamente con vegetación urbana, como sucede en la calzada Sur de Avenida Cerrillos con Avenida Américo Vespucio, en contraste con la mayoría de estas zonas termales, que registran coberturas vegetales medias y al menos presentan antejardines. En cuanto al sector que presenta usos del suelo urbano caracterizados por una baja densidad construida y alta cobertura vegetal, sólo se encuentra en un establecimiento educacional, que presenta gran cantidad de cobertura arbórea de copas desarrolladas, además de canchas deportivas. Cabe destacar, igualmente, el área residencial ubicada en la intersección de Av. Las Torres con Av. Américo Vespucio, que presenta viviendas sociales tipo bloques, de construcción reciente, que cuentan con una considerable cobertura de césped y árboles.

Finalmente, se encuentra la subzona de alta densidad residencial y baja cobertura vegetal emplazada en Av. del Ferrocarril, que presenta una considerable intensidad de construcción, en la cual difícilmente se visualiza espacio entre las viviendas, con escasos espacios públicos que no presentan mayor cobertura vegetal. 
FIGURA 9 | Subzonas climáticas para la comuna de Cerrillos

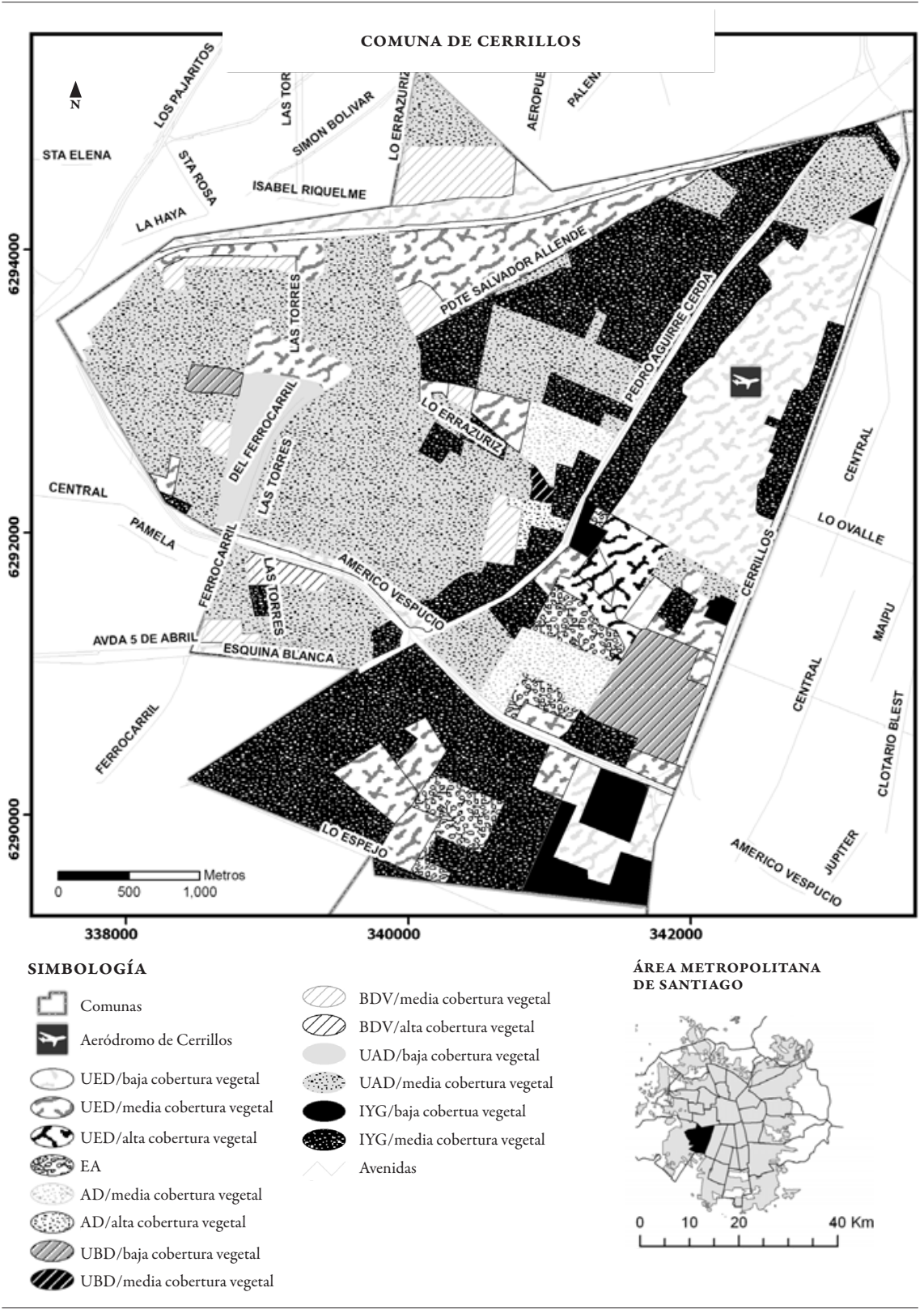

FUENTE ELABORACIÓN PROPIA. BASE PROYECTO OTAS, 2003. IMAGEN QUICKBIRD 2009, GOOGLE EARTH. PROYECCIÓN UTM, DATUM WGS86, HUSO 19s.

En cuanto a la distribución espacial de las temperaturas de emisión superficial en las subzonas termales urbanas (Figura 10), se aprecia la importancia de la relación es- 
pacial entre áreas cubiertas con mayor vegetación y temperaturas más bajas, que se ve alterada sólo en el caso de la urbanización de alta densidad, lo que se puede atribuir a factores específicos no considerados por la tipología, tales como el color de los techos o la materialidad de las viviendas. Las subzonas que presentan mayores temperaturas son las asociadas a suelos desnudos y residenciales extensivas de baja altura.

FIGURA 10 | Temperatura de emisión superficial promedio por subzona climática para la comuna de Cerrillos

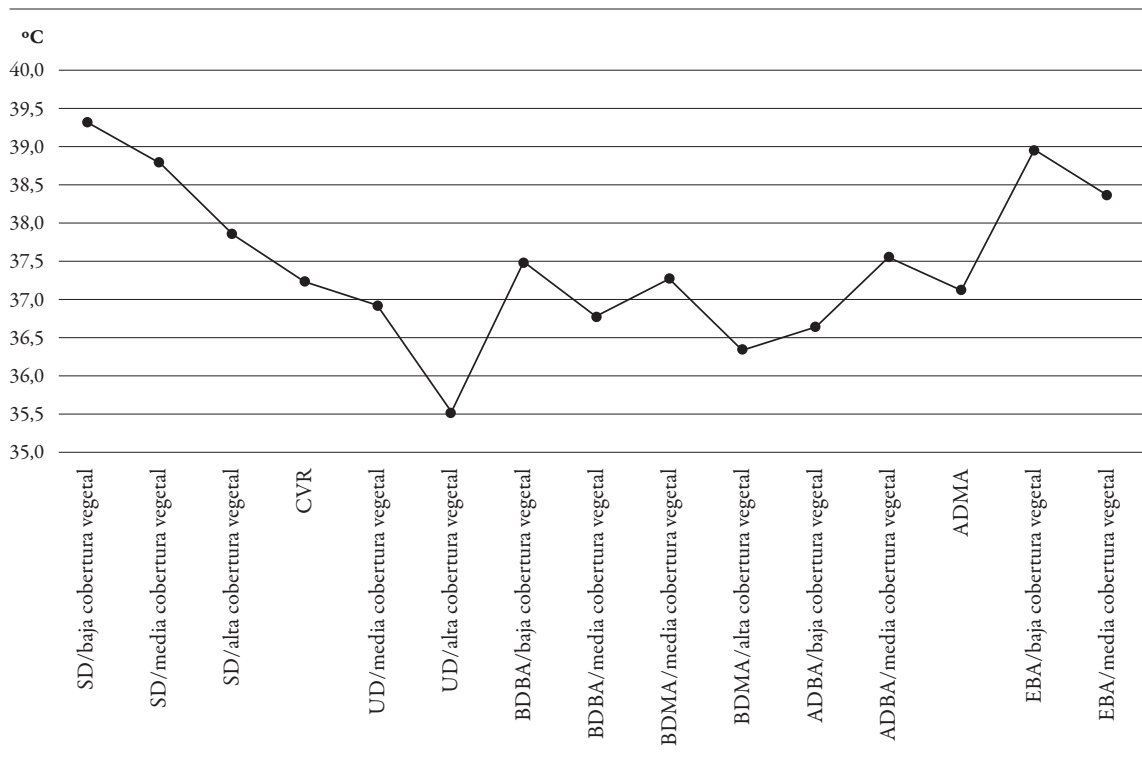

FUENTE ELABORACIÓN PROPIA.

En la comuna de Santiago (Figura 11) se produce una diferencia entre las subzonas climáticas que constituyen las áreas de urbanización de alta densidad. Aquellas que registran baja cobertura vegetal ocupan menos espacio en comparación con zonas con cobertura vegetal media. El patrón de localización de la primera se concentra entre Avenida Portugal y la Autopista Panamericana, desde Avenida Matta al Sur. En general, es bastante similar a la zona de media cobertura vegetal que se localiza al Poniente de la Autopista Panamericana, salvo por la cantidad de arbolado urbano y las viviendas que mantienen patios interiores con cobertura arbórea, lo que sería determinante en la diferenciación de las zonas termales. Se pueden atribuir a estos dos factores también las diferencias que se advierten entre los sectores del centro antiguo que presentan coberturas vegetales bajas y medias. La segunda subzona se localiza con mayor frecuencia, por ejemplo, en el área ubicada entre Av. Matucana, Bernardo O 'Higgins y Jorge Alessandri y en lugares como Av. Portales y varios patios interiores. Por otro lado, las diferencias entre las subzonas termales que forman parte de las áreas de galpones e industrias radican, por un lado, en el desarrollo del arbolado 
urbano y, por otro, en la intensidad de construcciones por predio. Por ejemplo, en la zona ubicada en Av. Isabel Riquelme con Av. Sta. Rosa existen galpones que utilizan la totalidad del predio, en el sector denominado "Mercado Persa Bío-Bío".

FIGURA 11 | Subzonas climáticas para la comuna de Santiago Centro

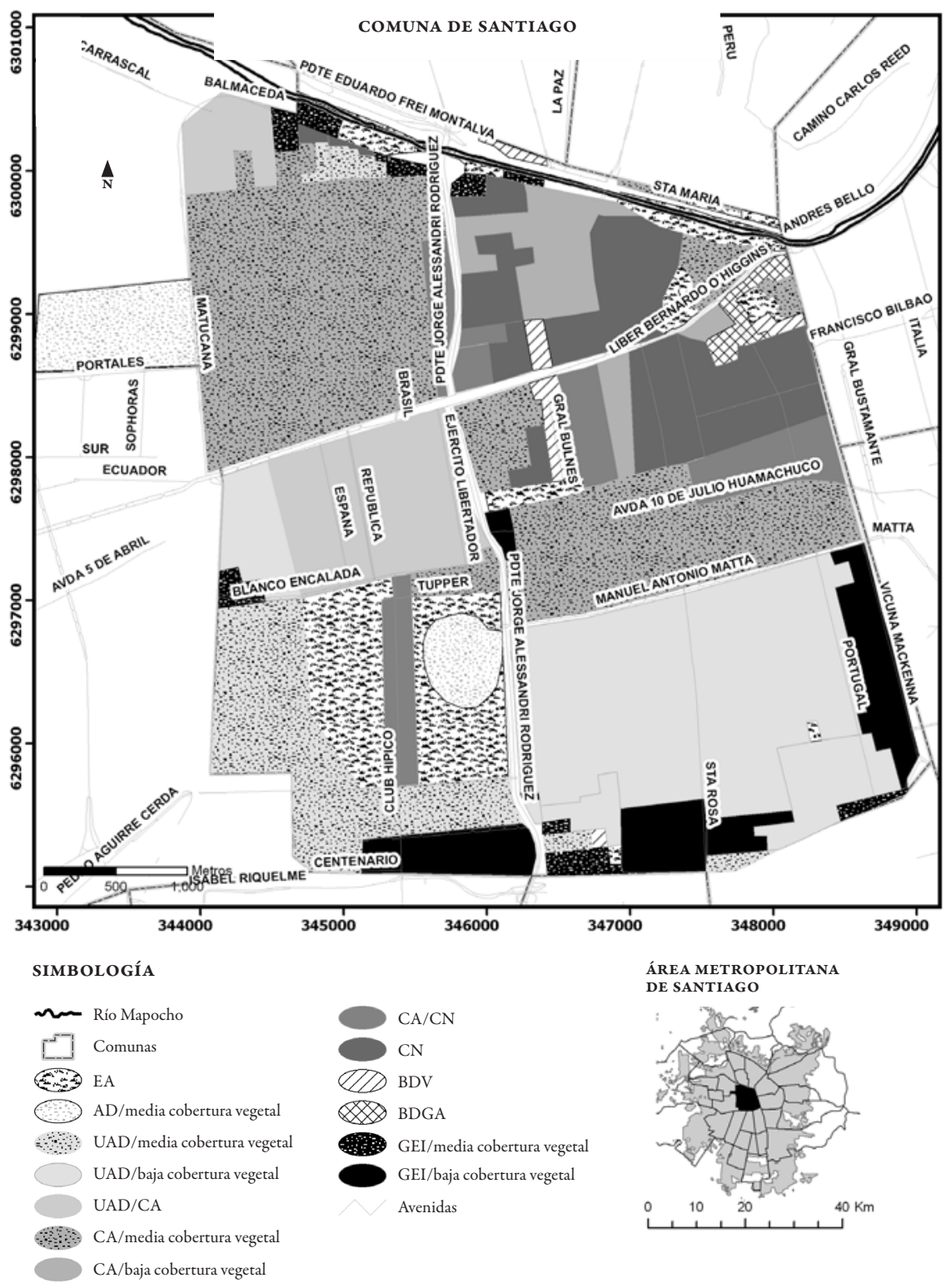

FUENTE ELABORACIÓN PROPIA. BASE PROYECTO OTAS, 2003. IMAGEN QUICKBIRD 2009, GOOGLE EARTH. PROYECCIÓN UTM, DATUM WGS86, HUSO 19s. 
Respecto al comportamiento térmico del mosaico de paisajes urbanos que se encuentra en la comuna de Santiago (Figura 12), correspondiente al casco histórico de la ciudad, las temperaturas más bajas se registran en aquellas subzonas de menor intensidad de urbanización, espacios abiertos (EA), asentamientos dispersos (AD), áreas residenciales de baja densidad y media y gran altura (BDV y BDGA), que se diferencian de las zonas urbanas caracterizadas por galpones e industrias y urbanización de alta densidad y del centro antiguo (UAD/CA). La presencia vegetacional en las subzonas termales, sin embargo, no genera diferencias significativas de temperatura, mayores a $0,5^{\circ} \mathrm{C}$.

FIGURA 12 |Temperatura de emisión superficial por subzona climática para la comuna de Santiago Centro

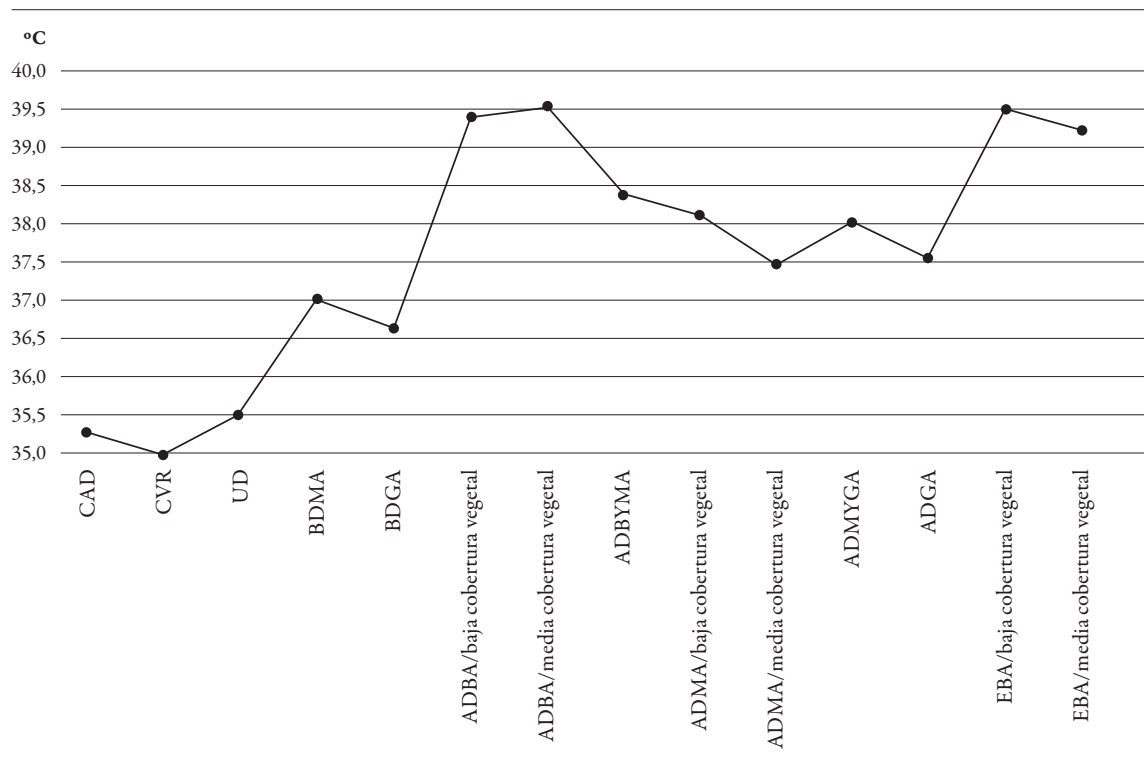

FUENTE ELABORACIÓN PROPIA.

\section{Discusión}

A escala de la ciudad en su totalidad, la integración de datos obtenidos por redes de estaciones de medición de características climáticas ha ratificado las distribuciones espaciales de las temperaturas del aire, separando la ciudad en dos secciones bien definidas, durante los períodos de ocurrencia de las mayores concentraciones de contaminantes. La interpolación de los datos proporcionados por un conjunto significativo de estaciones meteorológicas localizadas en distintas zonas morfológicas y geográficas de la ciudad se constituye en una primera representación a escala del dosel urbano, que complementa aproximaciones anteriores logradas con transectos móviles. Respecto a la distribución de la contaminación atmosférica, corres- 
pondiente al material microparticulado, es posible observar las grandes diferencias que presentan las concentraciones, según se midan en el sector Oriente o Poniente de la ciudad. Este último puede superar concentraciones que más que dupliquen aquellas registradas en el sector oriente durante los días y horas en que se alcanzan los valores más altos. Cuando se relacionan espacialmente los datos de temperatura del aire con los de contaminación por material particulado, se aprecian covariaciones que permiten sugerir que las diferencias térmicas generarían las brisas necesarias para transportar los contaminantes desde el sector Oriente al Poniente. Se sabe que las diferencias de temperatura registradas al interior de las áreas urbanas se deben especialmente a las variaciones en la intensidad de las densidades residenciales y a la presencia de usos y coberturas de suelos que concentran calor. Como estas últimas variables se relacionan a su vez con los niveles de ingresos económicos de la población, es posible observar que se cumplen en Santiago las condiciones que permiten clasificar a la contaminación atmosférica como injusticia ambiental. Se califica de esta forma a una zona que recibe en forma desproporcionalmente alta, en comparación con otras áreas de la ciudad, las cargas de contaminantes, desechos o cualquier otro elemento que degrade al medio ambiente. Cuando estas zonas afectadas ambientalmente pueden ser asociadas a ciertas vulnerabilidades de la población, como mayores niveles de pobreza, la injusticia ambiental se incluye en los problemas analizados por la ecología política.

Sin embargo, el escaso número de estaciones de medición de la contaminación atmosférica instaladas al interior de la ciudad de Santiago sólo permite representar distribuciones generales, correspondientes a concentraciones que permiten distinguir grandes zonas, pero que no son apropiadas para localizar e identificar fuentes específicas o determinar el éxito de las políticas de descontaminación. Los estudios más recientes señalan que la contaminación atmosférica al interior de las ciudades se concentra en las cercanías de las fuentes, como sucede a lo largo de las vías de transporte de mayor circulación. Para captar esta situación se debe disponer de estaciones de monitoreo distribuidas cerca de las fuentes, lo que no sucede en el caso de Santiago de Chile.

Respecto a los datos propiamente tales, se observa una gran variabilidad de concentración de contaminantes entre los días y a distintas horas de un mismo día. Para los días y horas de máxima concentración parece ser posible identificar un patrón espacial y temporal de su comportamiento, pero los análisis de días en que la calidad del aire se mantiene buena, señalan que las divisiones claras entre el Oriente y el Poniente de la ciudad tienden a diluirse.

Dado que la contaminación se concentra en ciertas horas del día, no es posible emplear los promedios diarios para adoptar decisiones sobre cuestiones como declaraciones de emergencia. Parece ser más conveniente realizar pronósticos de contaminación para el día siguiente con los datos registrados a las 20 horas.

Al cambiar de escala y aproximarse a la climatología de los niveles límite, la utilización de las zonas termales definidas por Sterwart y Oke, el año 2009, como base para la clasificación de la ciudad de Santiago, resulta sobre todo consecuente 
respecto a aspectos de la morfología urbana. Es posible reconocer que diferentes densidades de construcción dan cuenta de comportamientos térmicos similares. Sin embargo, la altitud de las edificaciones presenta mayores diferencias que deben ser estudiadas más profundamente en Santiago. Stewart y Oke (2009) consideraron la temperatura atmosférica para probar sus zonificaciones termales al interior de las ciudades; sin embargo este estudio considera las temperaturas de emisión superficial, razón por la cual existe una mayor influencia de factores específicos, como el color de los techos, la materialidad de las viviendas y las sombras (Griimmond y Oke, 1998; Meyn y Oke, 2009). En la comuna de Santiago Centro por ejemplo, zonas de alta densidad con edificaciones de mayor altura registran menor temperatura que la esperada, lo que podría deberse a la influencia del factor sombra y la geometría de calles y edificios, que pertenece a la capa del dosel urbano.

Respecto a los grupos socioeconómicos, y debido a que el último Censo de Población y Vivienda practicado en Chile corresponde al año 2002, no fue posible dar cuenta de procesos de urbanización más recientes acontecidos en las áreas estudiadas, así como la imposibilidad de abordar iniciativas públicas y privadas que pueden haber alterado el medio ambiente los últimos años.

Existen en los resultados obtenidos aspectos que llaman la atención, como por ejemplo, lo observado en la comuna de Cerrillos, desde donde comienzan a descender los niveles de contaminación hacia el centro de la ciudad y posteriormente hacia el sector oriente, lo que puede ser atribuido a la efectividad del cono de aproximación del aeródromo de Cerrillos al actuar como un corredor de viento, tema que ha estado en la controversia surgida a raíz de la urbanización de esta zona sin haber realizado una evaluación estratégica de sus impactos ambientales. A pesar de su enorme valor como corredor de viento, esta zona se encuentra actualmente abandonada, con bajos porcentajes de cobertura vegetal que coinciden con muy altas temperaturas de emisión superficial, constituyendo una enorme isla de calor, situación que podría revertirse si se decidiera destinar estos terrenos a un parque y a la conservación, de esta manera, del rol de corredor de vientos que aporta beneficios a la totalidad de la ciudad.

Diversos autores, entre ellos Nowak y MacPherson en el año 1993, señalaron que los parques y áreas verdes en la ciudad corresponden a verdaderas islas frías, que además proporcionan ventilación, conocida como "brisas de parques", lo que resulta evidente en todas las comunas estudiadas, y sobre todo en Santiago Centro.

La diversidad socioeconómica que se observa al interior de las comunas de la ciudad de Santiago es, en gran medida, manifestación del proceso de transición producido por una incipiente gentrificación (Sierralta, 2008 y Sabatini et al., 2007), por la cual los grupos de más altos ingresos comienzan a instalarse en condominios y ciudadelas localizadas en comunas tradicionalmente ocupadas en forma exclusiva por población pobre. Por otro lado, debe destacarse el proceso vertiginoso de construcción de edificios de altura en la comuna de Santiago Centro que se ha concretado en los años recientes, contando con subsidios del Estado para conseguir el repoblamiento de áreas de alta accesibilidad que se encontraban deterioradas. 
Vásquez (2008) y Salgado (2010) identificaron para la comuna de Peñalolén una clara relación entre las altas densidades residenciales y la carencia de cobertura vegetal, que constituye un patrón típico de ocupación del espacio con escasa calidad ambiental, asignado a los sectores sociales de menores ingresos. Asimismo, en esta comuna se observa el surgimiento de proyectos inmobiliarios orientados a población de mayores ingresos, correspondiendo con condominios cerrados, lo que ha significado una disminución en la escala de la segregación. Dichas zonas corresponden a hábitats segregados, con acceso restringido, que se han ido instalando en los últimos años al interior de la comuna y que se caracterizan por presentar una baja densidad residencial, viviendas uniformes y altos porcentajes de cobertura vegetal, constituyéndose en espacios de exclusividad y exclusión, dada la presencia de muros que los separan del resto de la población.

En la comuna de Santiago Centro se observa una importante presencia de población del grupo de ingresos medios-altos (C2) que convive con grupos de ingresos medios (C3) y medios-bajos (D). Tal coexistencia se debe, en gran medida, a procesos de renovación urbana que han traído consigo la instalación de proyectos residenciales destinados a grupos de ingresos medios-altos, que trabajan y/o estudian en la comuna, en espacios que hace sólo unos años eran habitados principalmente por grupos de menores ingresos.

\section{Conclusiones}

Existen marcados contrastes en la distribución de las temperaturas del aire y de las concentraciones de material particulado durante los días de concentraciones críticas de contaminación entre los sectores Oriente y Poniente de la ciudad. Tales diferencias son de un volumen lo suficientemente alto como para suponer una relación espacial entre ellas y el alto número de enfermedades y muertes que se han reportado para la ciudad de Santiago. Como estas diferencias afectan de manera relevante a los sectores de la ciudad donde reside la población más vulnerable, se puede concluir en la existencia de niveles de injusticia ambiental que requerirían medidas de mitigación y compensación especialmente destinadas a equilibrar la distribución espacial de los climas y contaminantes.

$\mathrm{Al}$ aumentar la resolución espacial, las zonas climáticas urbanas registran importantes diferencias en sus condiciones termales de superficie. Los bloques de edificios sociales, sin áreas verdes, ubicados al poniente de la ciudad, concentran las mayores acumulaciones de calor, mientras que los condominios cerrados de baja densidad, localizados al Oriente, concentran las islas frías. Las áreas residenciales de densidad media registran temperaturas elevadas, lo que también sucede con los edificios del centro nuevo y antiguo. Se puede señalar que en Santiago predominan las islas de calor por sobre las de frío y que éstas últimas parecen quedar restringidas a superficies de plazas y jardines, específicamente localizados. No obstante, en el examen de las tres comunas aparecen muchas subzonas intermedias que destacan la heterogeneidad de los climas urbanos, y por ello la complejidad de sus servicios ambientales y de sus efectos sobre la contaminación. 
De este modo, aunque es posible reconocer niveles generales de segregación social entre las comunas, es la diversidad y heterogeneidad socioambiental lo que predomina en la ciudad de Santiago. Ello hace más compleja la evaluación de las condiciones climáticas urbanas y complica la formulación de planes de gestión destinados a mitigar y adaptar los espacios urbanos a los cambios climáticos. Sin embargo, es claro que se deben formular políticas públicas e implementar inversiones destinadas a mitigar los efectos de los cambios climáticos en los barrios que registran las más altas temperaturas y que se asocian a construcciones de viviendas sociales. Como al mismo tiempo se ubican en sectores más afectados por la contaminación atmosférica, la construcción de equipamientos urbanos, amenidades y áreas verdes es un asunto de justicia ambiental. IEURE

\section{Referencias bibliográficas}

ADIMARK. (2004). Mapa socioeconómico de Chile. Nivel socioeconómico de los hogares del país basados en datos del Censo de Población y Vivienda del año 2002.

Budds, J. (2009). Contested $\mathrm{H}_{2} \mathrm{O}$ : Science, policy and politics in water resources management in Chile. Geoforum: 420-421.

Buzelli, M. (2008). Political Ecology of scale in urban air pollution monitoring. Transactions of the Institute of British Geographers, 33: 502-517.

Correa, E.N., Flores L.S. \& Lesino G. (2003). Isla de calor urbana: efecto de los pavimentos. Avances en Energias Renovables y Medio Ambiente. Vol. 7: 25-30. UNINCO-UNS-CONICET. Salta.

Crutzen, P. (2004). New Directions: The Growing Urban Heat and Pollution "Island" Effect - Impact on Chemistry and Climate. Atmospheric Environment. 38: 3539-3540.

Cuadrat, J.M, De la Riva, J., López, F. \& Martí, A. (1993). El medio ambiente urbano en Zaragoza. Observaciones sobre la "isla de calor". Anales de Geografía de la Universidad Complutense, Vol. 13: 127-138. Ed. Comp. Madrid.

Davenport, A., Grimmond, S., Oke, T. and Wieringa, J. (2000). Estimating the roughness of cities and sheltered country. Proc. $12^{\text {th }}$ AMS conf. on Appl. Climatology., Asheville, North Carolina. NC, 96-99.

Escobedo, F., Nowak, D., Wagner, J., De la Maza, C., Rodríguez, M., Crane, D. \& Hernández, J. (2006). The socioeconomics and management of Santiago de Chile's public urban forests. Urban Forestry \& Urban Greening 4: 105-114.

Grimmond, C. \& Oke, T. (1998). Heat Storage in Urban Areas: Local-Scale Observations and Evaluation of a Simple Mode. Journal of Applied Meteorology, Volumen 38: 922-940.

Kardinal Jusuf, S.; Wong, N.; Hagen, E.; Anggoro, R. \& Hong, Y. (2007). The influence of land use on the urban heat island in Singapore. Habitat International, article in press.

Lindberg, F., Eliasson, I. \& Holmer, B. (2003). Urban geometry and temperature variations. Proc. $5^{\text {th }}$ Int Conf Urban Climate. Vol. 1: 205-208.

Lowry, W. (1977). Empirical estimation of urban effects on climate: A problem analysis. Journal of Applied Meteorology, Volumne 16: 129-135. 
Meyns, S. \& Oke, T. (2009). Heat fluxes through roofs and their relevance to estimates of urban heat storage. Energy and Buildings 41:745-752.

Moral, F., Canito J. \& Álvarez, M. (2006). Representación gráfica de la distribución de la contaminación atmosférica de la ciudad de Badajoz mediante el uso del modelo de Rasch y de métodos geoestadísticos. España: Universidad de Extremadura.

Nowak, D. \& Macpherson, E.G.(1993). Cuantificación del impacto ambiental de los árboles en Chicago. Unasylva. 44 (173). 39-44. Roma.

Oke, T.R. (1987). Boundary Layer Climates. London: Routledge.

Oke, T.R (2004). Initial guidance to obtain representative meteorological observations at urban sites. Instruments and observing methods, report No. $81 \mathrm{WMO} / \mathrm{TD}-\mathrm{N}^{\circ} 1250.47$.

Ostro, B., Valdés, S. \& Sánchez, J.M. (1998). Los efectos en la salud de la contaminación atmosférica. Revista Estudio Públicos. N69. 125-154.

Pauleit, S. \& Duhme, F. (2000). Assessing the environmental performance of land cover types for urban planning. Landscape and Urban Planning, 52: 1-20.

Peña, M. (2008). Relationships between remotely sensed surface parameters associated with the urban heat sink formation in Santiago, Chile. International Journal of Remote Sensing, 29(15): 4385-4404.

Pelling, M. (2003). Towards a Political Ecology of Urban Environmental Risk: The case of Guyana. En K. Zimmerer \& T. Bassett (Eds.). Political Ecology, An Integrative Approach to Geography and Environment Development Studies. New York, London: The Guilford Press. 73-93.

Pérez González, M. E., García Rodríguez, M. P. \& Guerra Zaballos. A. (2003). Análisis del clima urbano a partir de imágenes de satélite en el centro peninsular español. Anales de Geografía de la Universidad Complutense. Vol. 23: 187-206.

Platt, R. (2006). Urban Watershed Management One Stream at Time. Environment Vol.48, No 4: 26-42.

Romero, H. (2004), Crecimiento Espacial de Santiago entre 1989 y 2003 y la Pérdida de Servicios Ambientales. En P. Tupper (Ed.). Hacer Ciudad. Santiago: Centro Chileno de Urbanismo. 179-201.

Romero, H. \& Vásquez, A. (2005). Evaluación ambiental del proceso de urbanización de las cuencas del piedemonte andino de Santiago de Chile. EURE Vol.31, No 94: 97-117. Santiago, Chile.

Sabatini, F., Wormald, G., Sierralta, C. \& Peter, P. (2007). Segregación residencial en Santiago: tendencias 1992-2002 y efectos vinculados con su escala geográfica. Documento de trabajo $N^{\circ} 37$, Instituto de Estudios Urbanos y Territoriales. Santiago, Chile. 37.

Salgado, M. (2010). Segregación socioambiental en la comuna de Peñalolén, Santiago de Chile. Tesis presentada al Departamento de Posgrado y Postítulo, Programa Interfacultades de la Universidad de Chile para optar al título de Magíster en Planificación y Gestión Ambiental. Santiago, Chile.

Shashua-bar, L., Potchter, O., Bitan, A., Boltansky, D. \& Yaakov, A. (2009). Microclimate modelling of street tree species effects within the varied urban morphology in the Mediterranean city of Tel Aviv, Israel. International journal of climatology, Vol 30: 44-57.

Sierralta, C. (2008). Efectos de la segregación residencial socioeconómica en los jóvenes de extracción popular en Santiago de Chile (1992-2002). Tesis presentada al Instituto de Estudios Urbanos y Territoriales de la Pontificia Universidad Católica de Chile para optar al Grado Académico de Magíster en Desarrollo Urbano. Santiago, Chile. 
Stewart, I.D. \& Oke, T. (2009). Classifying urban climate field sites by "local climate zones": The case of Nagano, Japan. Seventh International Conference on Urban Climate, 29 june-3 july, Yokohama.

Tablada. A., De Troyer. F., Blocken. B., Carmeliet, J. \& Verschure, H. (2009). On natural ventilation and thermal comfort in compact urban environments - the Old Havana case. Building and Environment 44: 1943-1958.

Trawick, P. (2003). Against the privatization of water: An indigenous model for improving existing laws and successfully governings commons. World Development, Vol. 31: 966-977.

Vásquez, A. (2008). Vegetación urbana y desigualdades socioeconómicas en la comuna de Peñalolén, Santiago de Chile. Una perspectiva de justicia ambiental. Tesis presentada al Departamento de Posgrado y Postítulo, Programa Interfacultades de la Universidad de Chile, para optar al grado de Magíster en Gestión y Planificación Ambiental. Santiago, Chile.

Vásquez, A. \& Romero, H. (2007). El libremercado de las áreas urbanas y la falta de justicia ambiental en la disponibilidad de áreas verdes en Santiago de Chile. En Actas del IX Coloquio Internacional de Geocrítica. Los Problemas del Mundo Actual. Soluciones y Alternativas desde la Geografia y las Ciencias Sociales. [En línea]. Barcelona: Universidad de Barcelona, 2007. http://www.ub.es/geocrit/9porto/hromero.htm

Villatoro, M., Henríquez C. \& Sancho, F. (2008). Comparación de los interpoladores IDW y Kriging en la variación espacial de PH, CA, CICE y P del suelo. Agronomia Costarricense. 32(1): 95-105.

Voogt, J.A. \& Oke, T.R. (2003). Thermal remote sensing of urban climates. Remote Sensing of Environment, $86: 370-384$.

Withford W., Ennos, A. \& Handley, J. (2001). City form and natural process: Indicators for the ecological performance of urban areas and their application to Merseyside, UK. Landscape and Urban Planning 57: 91-103. 